CRÍTICA, Revista Hispanoamericana de Filosofía

Vol. XXXII, No. 95 (agosto 2000): 71-102

\title{
VERDAD Y METÁFORA: UNA APROXIMACIÓN PRAGMÁTICA
}

EDUARDO FERMANDOIS

Universidad Libre de Berlín

\section{La pregunta central y una pregunta previa}

Nuestro concepto habitual de verdad, manzana de la discordia en tantas y tan largas discusiones filosóficas, posee para la metáfora una importancia meramente negativa. Es una impronta del enunciado metáforico no ser verdadero, o serlo tan sólo en un sentido trivial. Decir que las palabras son las flores de la boca es falso, pues una palabra es una entidad lingüística que sería absurdo buscar en un jardín. Y decir que los seres humanos no somos islas, es verdadero, pero a la vez trivial: quien simplemente conozca el significado de las expresiones castellanas "ser humano" e "isla", no le dedicaría siquiera un instante a la pregunta de

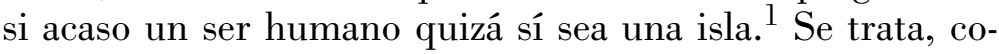
mo digo, de una impronta, i.e., de un rasgo constitutivo del

1 Metáforas "doblemente verdaderas" (twice true), a saber, enunciados que son verdaderos tanto en una lectura literal como en una metafórica, no constituyen una excepción a estos dos criterios de lo metafórico (falsedad, obvia verdad). Si alguien me dice que Varsovia es una ciudad fría, sólo lo tomaré metafóricamente - como una alusión, por ejemplo, a un problema de política internacional-, si se da por descontado que estoy al tanto del clima de Varsovia, es decir, si en la situación correspondiente la información cuenta como obvia. Lo que el fenómeno observado por Ted Cohen pone realmente de manifiesto es la dependencia contextual de la identificación e interpretación de metáforas, a la que me referiré en el cuarto apartado. Cfr. Ted Cohen, 
fenómeno metafórico. Si el enunciado "Las palabras son las flores de la boca" fuese verdadero, en el sentido habitual de la palabra "verdadero", ello implicaría: primero, que la extensión del predicado "flor" sería considerablemente mayor que su extensión actual; segundo, que estaríamos frente a un enunciado literal; y por ende, tercero, que yo habría cambiado de tema.

Todo esto es más o menos obvio, pero por obvio tendemos a callarlo y a olvidarlo. No así Donald Davidson, cuyo influyente artículo "Qué significan las metáforas"2 contiene de principio a fin el siguiente recordatorio: para que un enunciado pueda ser considerado metafórico es esencial que no sea verdadero, en el sentido habitual del término. Ahora bien, es difícil negar que, al mismo tiempo, decir de las palabras que son las flores de la boca podría ser, en otro sentido del término, completamente verdadero. Al menos es posible discutir si esta metáfora presenta una visión adecuada o correcta del lenguaje. Quien no estuviese de acuerdo, podría plantear que se tiene una concepción más apropiada del lenguaje si se ven las palabras como herramientas. Y también sobre esta metáfora se podrá discutir, es más, se ha discutido de hecho. Hay quienes han observado más problemas que ventajas en la propuesta rortyana de que las palabras (o "léxicos") no son más que herramientas destinadas a un eficiente manejo de la realidad. Estos casos demuestran que lo metáforico no nos transporta fuera del ámbito de lo debatible, lo argüible, lo justificable - fuera, por lo tanto, del ámbito de lo verdadero y lo falso. Pues bien, ¿cuál es ese otro sentido de la palabra "verdadero" en que una metáfora puede ser, o no, verdadera? ¿En qué

"Notes on Metaphor", Journal of Aesthetics and Art Criticism, no. 34, 1976, pp. 249-259.

2 Donald Davidson, De la verdad y la interpretación. Fundamentales contribuciones a la filosofía del lenguaje, Barcelona, 1995, pp. 245-262. 
consiste la verdad de una metáfora? Ésta es la pregunta central que motiva el presente trabajo. Su primera parte (la sección 2) consiste en un examen crítico de una posible respuesta, o mejor, de un posible modelo de respuesta; en la segunda parte (las secciones 3, 4 y 5) desarrollo una propuesta alternativa. Como lo sugiere su título, el trabajo no representa una respuesta exhaustiva a la pregunta central; mi intención es aproximarme a una respuesta.

Sin embargo, habiendo mencionado a Davidson, no puedo entrar en materia sin examinar la pregunta precedente de si realmente es necesario o pertinente buscar un concepto de verdad metafórica. Davidson piensa, en efecto, que no lo es. En su opinión, no tiene sentido atribuir verdad a una metáfora, fundamentalmente por dos razones: primero, porque un enunciado metafórico no posee un contenido semántico propio, i.e., distinto de su contenido semántico literal, de acuerdo con el cual, como vimos, se trata y tiene que tratar de un enunciado falso o trivialmente verdadero. Y segundo, porque, como veremos más adelante muchas metáforas incluyen aspectos no proposicionales; muchas metáforas - y acaso las mejores - evocan, por ejemplo, imágenes y sentimientos. Al mismo tiempo, Davidson no niega, sino todo lo contrario, que el discurso metafórico sea un importante factor en nuestra experiencia cognoscitiva del mundo, distanciándose explícitamente de tradiciones como las del empirismo, tanto el clásico como el lógico, que no ven en la metáfora más que un recurso ornamental. Pero aquí precisamente surge el problema: tan pronto como se niega que una metáfora pueda ser en algún sentido verdadera, no parece lícito seguir hablando de su papel cognoscitivo. Davidson describe la relación entre una metáfora y aquellas verdades literales a las que ésta nos puede conducir en una terminología causalista: el enunciado metafórico "suscita" ("provoca", "ocasiona" o hasta "detona") el reconocimiento de nuevas verdades 
literales. ${ }^{3}$ Pero si es ése el tipo de relación en juego, no parece haber cabida para la idea de que una metáfora es capaz de cumplir una función específicamente cognoscitiva. Porque si es ése el tipo de relación en juego, haber escuchado o leído una metáfora no podría constituir una razón para aceptar ciertos enunciados literales como nuevas verdades. Bien pueden también unos buenos tequilas causar el reconocimiento de alguna insospechada verdad literal. Unas horas más tarde puede causarlo también un café cargado. Pero no por ello hablamos de una función cognoscitiva del tequila o del café, sencillamente porque ni uno ni otro son o brindan razones que respalden una determinada creencia. El problema en que veo inmerso a Davidson puede ser descrito como sigue: al no existir un significado específicamente metafórico, y al haber aspectos no proposicionales de por medio, ${ }^{4}$ Davidson no cree poder hablar de una verdad metafórica. Pero al no hacerlo, la atribución de un valor cognoscitivo a la metáfora queda reducida a un decir por decir, a una mera confesión de labios. En mi opinión, sólo es posible salir de este problema, si se logra encontrar aquello que Davidson sencillamente no busca: un concepto de verdad que sea aplicable a enunciados metafóricos, pese a que éstos no poseen un contenido semántico distinto de su contenido literal y pese a que hay en juego elementos no proposicionales.

Una última observación antes de comenzar: decir que Davidson nos recuerda lo más o menos obvio podría pare-

3 Más tarde Rorty llevará esta explicación causal hasta sus últimas consecuencias. Cfr. Richard Rorty, "Unfamiliar Noises: Hesse and Davidson on Metaphor", en su Objectivity, Relativism, and Truth. Philosophical Papers, vol. 1, Cambridge, Mass., 1991, pp. 162-172.

4 Creo correcto e importante insistir, como lo hace Davidson, en los aspectos no proposicionales (volveré a este punto más adelante). La crítica davidsoniana al concepto de significado metafórico merece, en cambio, un juicio más diferenciado. 
cer una afirmación irónica; sin embargo, no ha sido ésa mi intención. No sólo importa tener presente que un enunciado metafórico es literalmente falso o trivial, por ser éste un aspecto constitutivo de lo metafórico. Importa además, porque el recordatorio contiene, por así decir, un indicio: el indicio de que el concepto de verdad metafórica que buscamos sea probablemente un concepto muy distinto del de verdad literal, quiero decir, un concepto de verdad cuya gramática resulte ser diferente de la gramática del concepto de verdad literal.

\section{2. ¿Verdad metafórica como verdad literal indirecta?}

La explicación sin duda más a la mano de la verdad de una metáfora dice más o menos así: un enunciado metafórico será considerado verdadero, si de alguna manera nos conduce al reconocimiento de verdades literales. ${ }^{5}$ La idea es sencilla y transparente: al interpretar una metáfora accedemos tarde o temprano a ciertos enunciados literales; pues bien, si éstos son verdaderos, en el sentido habitual de la palabra, entonces podremos atribuirle verdad a la metáfora misma. El concepto de verdad metafórica sería analizado así mediante el concepto de verdad literal. Y lo específico de la verdad metafórica, es decir, lo que caracteriza a aquel sentido distinto de verdad que aquí nos interesa, estaría en el modo indirecto en que una metáfora comunica su verdad: es vía la verdad literal de aquellos enunciados en que desemboca la interpretación de una metáfora, que ésta

5 Diversas teorías de la metáfora ofrecen diversas explicaciones de cómo una metáfora puede conducir a tal reconocimiento: si por medio de una comparación tácita (teoría de la comparación), o introduciendo una expresión en lugar de otra (teoría de la sustitución), o mediante una implicación conversacional (Grice), o queriendo decir algo indirectamente (Searle). Estas diferencias no importan aquí y por ello hablo a continuación de un modelo de verdad metafórica. 
puede ser considerada verdadera. En una palabra, verdad metafórica es verdad literal indirecta. ${ }^{6}$

Este modelo explicativo goza de una intuitiva plausibilidad de la que es necesario dar cuenta (volveré sobre esto más adelante). Sin embargo, sus deficiencias no son pocas y poseen además un cierto denominador común, lo cual pareciera apuntar a un problema de fondo en este, como lo llamaré, "modelo de la verdad indirecta". A continuación quiero reseñar brevemente cuatro críticas, cuyo denominador común es la tesis de que dicho modelo entra en conflicto con aspectos precisamente distintivos del discurso metafórico. De ser las críticas acertadas, tendríamos entonces que el modelo no logra dar con lo específicamente metafórico de la verdad metafórica y que es ése su problema de fondo.

a) El carácter abierto de un enunciado metafórico. Una de las características intrínsecas de toda metáfora viva es su capacidad de sugerir muchas y, en rigor, infinitas lecturas. La idea de que en un determinado momento se llegue a la interpretación, o la interpretación completa, es una idea ajena al concepto de lo metafórico. Propio de una metáfora, como observa Cavell, es más bien el "etcétera" con que acaba normalmente su comentario o paráfrasis. ${ }^{7}$ Un intérprete sensible y culto siempre podrá encontrar un comentario original a metáforas como "Las palabras son las flores de la boca", "La arquitectura es música petrificada" o "El Señor es mi pastor". Ahora bien, si la idea de inter-

${ }^{6}$ Refiriéndose a lo mismo, Cooper habla de una "verdad vicaria" (vicarious truth): el enunciado metafórico aparece como si estuviera "en lugar de" o "sustituyendo a" un determinado número de enunciados literalmente verdaderos. Cfr. David E. Cooper, Metaphor, Oxford, 1986, pp. 200-216.

7 Cfr. Stanley Cavell, "Aesthetic Problems of Modern Philosophy", recopilado en su libro Must We Mean All What We Say?, Cambridge, Mass., 1976. 
pretación metafórica es necesariamente indeterminada, no queda claro cuáles y cuántos enunciados literales tendrían que ser verdaderos para que lo fuera también el enunciado metafórico. Ésta es la primera dificultad con que se topa el modelo de la verdad indirecta.

Veamos una posible objeción. Con apoyo en teorías de la metáfora como las de Grice o de Searle, se podría trabajar con la idea de que un enunciado metáforico es verdadero cuando lo son (la mayoría de) los enunciados implicados por un hablante (Grice), es decir, cuando es literalmente verdadero aquello que el hablante quiere decir indirectamente (Searle). ${ }^{8}$ Por cierto, ésta es una de las posibles versiones del modelo que estamos examinando y seguramente la más difundida. Ahora bien, la objeción consistiría en decir que la explicación que acabo de referir no contradice en absoluto el hecho de que una metáfora pueda generar más y más lecturas; no lo contradice, puesto que el hablante simplemente no tiene la intención de afirmar todo lo que pueda ser asociado con su metáfora. De igual modo, no sería sensato pretender identificar todas las lecturas que se le ocurran a un intérprete con la o las intenciones asertóricas del hablante. Así pues, la verdad de una afirmación metafórica seguiría siendo la verdad literal de lo que el hablante quiso decir y esto no estaría en contradicción con el carácter abierto de la metáfora. ${ }^{9}$ El problema de esta argumentación radica en que es correcta: en efecto,

${ }^{8}$ Existen, sin duda, diferencias entre los tratamientos de Grice y Searle: fundamentalmente, la mayor sensibilidad de Grice con respecto a la dimensión contextual y el status menos pretencioso de sus "máximas" en comparación con las reglas elaboradas por Searle. Por lo mismo, mi crítica se dirige sobre todo a la teoría metafórica de este último. Cfr. H. Paul Grice, "Logic and Conversation", en P. Cole y J. Morgan (eds.), Syntax and Semantics, vol. 3, Nueva York, 1975; y John Searle, "Metaphor", en su Expression and Meaning, Cambridge, Mass., 1979.

9 Aunque sin referencia a la cuestión de la verdad metafórica, este 
un enfoque como el de Searle o de Grice no contradice el carácter abierto de lo metafórico; no obstante, y ésta es mi objeción, tampoco da cuenta de él. La inexistencia de un límite interpretativo en el caso de metáforas vivas o fuertes ${ }^{10}$ es y seguirá siendo una viga en el ojo para todo modelo que defina o analice la verdad metafórica en términos de verdad literal.

b) Redes metafóricas. La segunda crítica arranca de la siguiente observación: una buena metáfora suele despertar en el intérprete no sólo una cantidad indefinida de pensamientos literales, sino también pensamientos metafóricos. Los intérpretes suelen extender o expandir una metáfora mediante otras, generando algo así como cadenas o redes metafóricas. 11 La metáfora "Un poema es un faisán” nos permite ver que un poema sabe muy bien de su singular belleza, que no tiene intención de ocultar que lo sabe, que sólo a veces despliega su plumaje, que su coqueta autocomplacencia puede llegar hasta la soberbia... todo lo cual es tan cierto como metafórico. No sería justo decir que la condición expansiva de una buena metáfora está en contradicción directa con el modelo que critico; pero una cierta tensión me parece innegable. No hay contradicción, pues el modelo de la verdad indirecta en ningún momento niega que la interpretación de una metáfora contenga en muchos casos, como algo de hecho, otros enunciados metafóricos; pero hay una tensión, en la medida en que la idea di-

argumento se encuentra en Merrie Bergmann, "Metaphorical Assertions", Philosophical Review, XCI, 1982, pp. 230 ss.

${ }^{10}$ Black considera como fuertes aquellas metáforas que cumplen en un grado alto los criterios de "énfasis" y "resonancia": una metáfora es enfática cuando ninguna de sus palabras puede ser sustituida por otras y posee resonancia cuando es rica en implicaciones. Cfr. Max Black, "More about Metaphor", Dialéctica, 31, 1977, pp. 431-457.

${ }^{11} C f r$. sobre este fenómeno Lynne Tirrell, "Extending: The Structure of Metaphor", Noûs, 23, 1989, pp. 17-34. 
rectriz, la que anima y organiza dicho modelo, es la idea de una traducción de enunciados metafóricos a enunciados literales. En consecuencia, si bien no se niega el fenómeno de las redes metafóricas, es inevitable que se lo considere accidental y secundario: un accesorio, no un rasgo típico de la buena metáfora.

c) Las virtudes no proposicionales de una buena metáfora. Ver al hombre como lobo del hombre va ligado a sensaciones de rechazo, temor o desconfianza, esto es, a aspectos emocionales no susceptibles de expresión proposicional. Asimismo, las metáforas suelen sugerir imágenes, escenarios, pueden crear o transformar una atmósfera: "y el verso cae al alma como al pasto el rocío" (Neruda); "el sueño teje un ovillo de seda de la enmarañada manga de las preocupaciones" (Shakespeare). Una imagen vívida puede ser, qué duda cabe, el condimento decisivo de un buen plato metafórico. Ahora bien, pretender averiguar cuántas proposiciones transmite una imagen es, como diría Wittgenstein, pretender decir cómo suena un clarinete. Acaso la clasificación más profunda de teorías modernas de la metáfora sea la propuesta por Martin Davies entre "teorías proposicionales" (proposition theories) y "teorías de la imagen" (image theories), y hay buenas razones para compartir su simpatía por estas últimas. ${ }^{12}$ Como bien señala Davidson, en la vida existen importantes experiencias que no pueden ser reducidas a la aprehensión de un contenido proposicional, y una función central de metáforas vivas y refrescantes es la de ser ocasión para tales experiencias. ${ }^{13}$ El efecto de metáforas fuertes, sin excluirlo, tampoco se

12 Cfr. Martin Davies, "Idiom and Metaphor", en Aristotelian Society Proceedings, LXXXIII, 1982/1983, pp. 67-85.

13 Cfr. Donald Davidson, "Reply to Oliver Scholz", en R. Stoecker (ed.), Reflecting Davidson, Berlín/Nueva York 1993, p. 173. En "Qué significan las metáforas" Davidson pregunta cuántas proposiciones transmite una fotografía, sólo para indicar que se trata de una ma- 
agota en lo articulado lingüísticamente: la metáfora incluye y transciende lo proposicional. El intento de reducir su verdad a un conjunto de verdades literales implica, por lo tanto, dejar fuera experiencias no susceptibles de aprehensión proposicional, que se cuentan, sin embargo, entre los más preciados encantos de la metáfora.

d) La dinámica de la interpretación metafórica. Si bien no puede ser casual que al entrar en una discusión sobre la verdad de un enunciado metafórico exista la inevitable tendencia a discutir enunciados literales, no es cierto que el intérprete comience revisando, de modo por así decir neutral, cuáles y cuántos pensamientos verdaderos y falsos contiene lo escuchado, tras lo cual, y de ser el balance positivo, le atribuya verdad a la metáfora misma. A la hora de describir la interpretación metafórica, el modelo de la verdad indirecta tendría que hacerlo en tales términos. Sin embargo, esa descripción impide apreciar el papel activo y productivo del intérprete, quien antes que nada encau$z a$ lo que ha escuchado hacia lo instructivo y verdadero, tornando, él mismo, lo insólito en interesante. La metáfora es en sí misma una promesa que el intérprete se encarga de cumplir. Hay pues un rendimiento interpretativo que comienza mucho antes de que se evalúe lo que una metáfora supuestamente sugiere "por sí sola". De hecho, como veremos dentro de poco, dicho rendimiento interpretativo se manifiesta ya en la identificación de una metáfora como tal.

Lo que intento poner de relieve mediante estas cuatro críticas es lo siguiente: aceptar la tesis de que una metáfora comunica su verdad indirectamente implica distorsionar el fenómeno metafórico en aspectos cruciales. Por lo mismo, el modelo de la verdad indirecta es incapaz de elaborar

la pregunta, pues "[l]as palabras no son la moneda apropiada para intercambiar por una imagen" (Davidson, op. cit., p. 261). 
lo específicamente metafórico de la verdad metafórica. Su propuesta se mueve todavía dentro del territorio delineado por la gramática de la verdad literal. Por lo demás, dicho modelo y las correspondientes teorías de la metáfora incurren en una falacia. Cuando se piensa en términos de verdad indirecta, se opera, implícita o explícitamente, con la idea de un primado del discurso literal respecto del discurso metafórico. Dicho primado se reflejaría en el hecho de que un enunciado metafórico sugiere o da a entender algo que, al menos en principio, sería expresable por uno o varios enunciados literales. La falacia está en pretender inferir a partir del indudable primado conceptual del significado literal un primado funcional del discurso literal. ${ }^{14}$ Para comprender una metáfora debemos comprender las palabras y la oración correspondientes en su sentido literal - en esto consiste el primado lógico o conceptual del significado literal. Pero de éste no se sigue sin más que la función de un enunciado metafórico sea derivada o secundaria respecto de la función de un enunciado literal. Eso habría que comprobarlo y, como hemos visto, hacerlo no resulta nada fácil, si no se pretende desfigurar al mismo tiempo lo que sea una metáfora. ¿Por qué no intentar entonces la hipótesis contraria: la de que el discurso metafórico posee una función propia, distinta y no derivada?

\section{Una metodología pragmática: verdad sin representación}

Todo lo que sigue es una aproximación, y no más que una aproximación, a un enfoque alternativo de verdad metafórica. Quisiera comenzar con un punto de carácter me-

14 Esta falacia es expuesta claramente en los dos siguientes artículos: Martin Seel, "Am Beispiel der Metapher", en Forum für Philosophie Bad Homburg (eds.), Intentionalitat und Verstehen, Fráncfort del Meno, 1990, pp. 237-272; Dan Sperber y Deirdre Wilson, "Loose Talk", Proceedings of the Aristotelian Society, 86, 1985/1986, pp. 153-171. 
todológico, concretamente, con lo que se podría denominar la originalidad metodológica del pragmatismo en cuanto teoría de la verdad (de la verdad literal, claro está). El pragmatismo representa, en primer lugar, un nuevo modo de abordar el viejo tema: en vez de centrar nuestra investigación conceptual acerca de la verdad en la idea de un contenido - el contenido descriptivo de oraciones o creencias que consideramos verdaderas-, el pragmatismo propone que nos centremos en la práctica de afirmarlas y aceptarlas como verdaderas. La idea de fondo - me limito aquí a nombrarla - es que cuando llamamos a una oración "verdadera", más que describirla lo que hacemos es recomendarla. Como ha mostrado recientemente Robert Brandom, ésta es la manera más general y, por así decir, más neutral, de describir la estrategia explicativa del pragmatismo con relación al tema de la verdad. Esto quiere decir que es posible distinguir la estrategia así descrita de afirmaciones más específicas, y por cierto más discutibles, como las de que lo verdadero es lo útil, lo verificable, u otros lemas de lo que Brandom llama el "pragmatismo estereotipado". ${ }^{15}$ Cuando James, por ejemplo, escribe que "[l]a verdad de una idea no es una propiedad estancada inherente a ella", sino que "[l]a verdad acontece a una idea", ${ }^{16}$ una lectura posible

15 Cfr. Robert Brandom, "Pragmatism, Phenomenalism, Truth Talk", Midwest Studies in Philosophy, XII, 1987, pp. 75 ss. Otra manera de formular la idea que orienta al pragmatismo, en la versión no estereotipada que interesa a Brandom, es diciendo que enunciados del tipo "p es verdadero" no funcionan, pese a la analogía gramatical, como descripciones ("La mesa es roja"), sino como performativos ("Te prometo que vendré").

16 William James, "Concepción de la verdad según el pragmatismo", en J.A. Nicolás y M.J. Frápoli (eds.), Teorías de la verdad en el siglo Xx, Madrid 1997, p. 97. Se malinterpretan las observaciones de James o Dewey sobre verdad, si se las lee como el intento de dar un análisis lógico, semántico o conceptual, i.e., una definición del predicado "verdadero" (lamentablemente, ellos mismos se valen 
sería decir que James nos está proponiendo una nueva manera de plantear el tema. En vez de preguntarnos: ¿qué propiedad distingue a los enunciados considerados verdaderos?, podemos preguntarnos: ¿qué hacemos cuando los consideramos verdaderos? Cuál sea la respuesta correcta a esta pregunta, no es lo que me interesa en este contexto; ${ }^{17}$ lo que me interesa es la pregunta. Ella revela que las ideas de correspondencia y representación dejan de ser punto de partida o eje de referencia en la investigación pragmática sobre la verdad —y éste es el aspecto metodológico que me interesa recalcar.

La motivación anti-representacionalista del pragmatismo en cuanto filosofía de la verdad es un primer paso en la búsqueda de un concepto de verdad metafórica. Pues, evidentemente, la función cognoscitiva de una metáfora no puede consistir en representar correctamente un estado de cosas. Pero más aún, lo verdadero de una metáfora no puede radicar en su contenido: después de todo, y como vimos al comienzo, es esencial que su contenido sea falso (o palmariamente verdadero). Como veremos más adelante, esto no significa que el contenido de una metáfora sea irrelevante para su verdad; significa que la verdad de una metáfora no puede consistir en la expresión de un contenido. Como espero ir mostrando poco a poco, una de las claves para en-

de formulaciones que dan pie a este malentendido). C $f r$. al respecto Barry Allen, Truth in Philosophy, Cambridge, Mass./Londres, Inglaterra, 1993, pp. $62 \mathrm{s.}$

17 Me inclino a lo que Brandom llama "pragmatismo normativo", a saber, la tesis de que considerar algo verdadero equivale a asumir ciertos derechos y deberes en un "espacio de razones". Aunque los conceptos de verdad y justificación no son idénticos, la única manera de escapar a un realismo metafísico, en último término incomprensible, es ver estos dos conceptos íntimamente conectados. Sobre la diferencia (articulada en términos de la diferencia entre primera y tercera persona) y la íntima conexión, cfr. Albrecht Wellmer, "Der Streit um die Wahrheit. Pragmatismus ohne regulative Ideen" (manuscrito). 
tender qué sea la verdad metafórica es precisamente caer en cuenta de que la noción de contenido, si nos centramos en ella, nos aparta del buen camino, pero que no obstante desempeña un papel importante. En cualquier caso, el antirepresentacionalismo pragmático nos abre la posibilidad de investigar el tema de la verdad sin necesidad de centrarnos en la idea de un contenido representativo. Mirándolo bien, era lo que precisamente hacía el modelo que criticamos en el apartado anterior, al pretender localizar la verdad de una metáfora en un presumible mensaje por descifrar. Su eje de referencia era la idea de un contenido, aquel que sería expresado indirectamente por la metáfora misma y directamente por los enunciados a que conduce su interpretación. En el fracaso de ese modelo tenemos una buena razón para preferir una metodología pragmática. Así, la pregunta que se halla en la base de todo lo que sigue no es: ¿qué expresa una metáfora verdadera?, sino: ¿qué hacemos al proponer o tomar una metafóra como verdadera?

\section{La noción goodmaniana de rightness}

Así planteada la pregunta, quiero llamar ahora la atención sobre una noción propuesta por un autor al que muchos consideran parte de la tradición pragmática y al que Rorty aplica incluso la algo antojadiza etiqueta de "neopragmático". 18 El autor es Nelson Goodman y la noción es rightness. No conozco una traducción directa de este término que sea siempre satisfactoria: "corrección" pareciera ser una categoría exclusivamente moral; "adecuación” evoca una conocida teoría de la verdad, pero nada

18 Tal como en el caso de Davidson, no está claro que Goodman mismo acepte esta clasificación (más bien pareciera que no). Con relación al inflacionario uso actual del rótulo "(neo)pragmatismo", el texto "Pragmatics and Pragmatism" de Robert Brandom (manuscrito, 1998) es una buena fuente de aclaración sistemática. 
pragmática. Dado que ninguno de los dos términos convence plenamente, me serviré de ambos, dependiendo de la ocasión; ${ }^{19}$ hablaré también de "corrección pragmática" y a veces usaré simplemente el vocablo inglés.

Comencemos preguntando de qué cosas diríamos que pueden ser correctas pragmáticamente, de qué es predicable "right". En Reconceptions in Philosophy and Other Arts and Sciences Goodman y la coautora Catherine Elgin presentan una larga lista: "No sólo afirmaciones, sino también órdenes y preguntas, palabras, categorías, imágenes, diagramas, muestras (samples), esbozos, pasajes y ejecuciones musicales, y símbolos de cualquier otro tipo pueden ser correctos (right) o incorrectos (wrong)." ${ }^{20}$ Mi propósito — no será difícil adivinarlo - es ver qué ocurre si agregamos a esta lista, como nuevo ítem, los enunciados metafóricos. $^{21}$

Pero, ¿qué es o en qué consiste esta rightness o corrección pragmática? Goodman y Elgin plantean enfáticamente

19 Hasta donde veo, es lo que también hace Carlos Thiebaut en su traducción de Ways fo Worldmaking [Nelson Goodman, Maneras de hacer mundos, Madrid, 1990]. Thiebaut emplea también las expresiones "validez" y "ajuste".

20 Nelson Goodman y Catherine Z. Elgin, Reconceptions in Philosophy and Other Arts and Sciences, Routledge, Londres, 1988, pp. 155s.

${ }^{21}$ Otro ítem que sería interesante agregar, por su relevancia en textos filosóficos, son los buenos ejemplos. Lamentablemente y un poco inexplicablemente, ni Goodman, ni Elgin, ni juntos ni por separado, aplican la noción de rightness en forma explícita al caso de la metáfora. Si bien al examinar dicha noción en el capítulo II de Reconceptions se refieren ocasionalmente a metáforas, en los textos dedicados directamente al tema de la metáfora y su verdad, ninguno de los dos abandona el marco conceptual del concepto tradicional (i.e., proposicional) de verdad. Cfr. Nelson Goodman, Languages of Art, Indianápolis, 1976 (cap. II, secciones 5-8) y Of Mind and Other Matters, Cambridge/Mass., 1884 (cap. III, sección 2); Catherine Elgin, With Reference to Reference, Indianápolis/Cambridge 1983 (cap. IV). 
que no hay una definición formal de este concepto o criterios para su aplicación; lo que hay son ejemplos y una caracterización a grandes rasgos. He aquí tres de los ejemplos presentados por Goodman y Elgin: a) Un médico le dice a un paciente desalentado: "Usted está haciendo progresos." No es difícil imaginar una situación en que siendo este enunciado falso, sea a la vez adecuado. Considerarlo adecuado o inadecuado dependerá de cuál sea el efecto que se pretenda lograr con lo dicho. b) El enunciado "La nieve es blanca" es ciertamente verdadero, pero es incorrecto si lo que se está discutiendo es la pregunta por la densidad del granito: incorrecto por irrelevante. c) La hilaridad que provoca un discurso salpicado de notas jocosas es una actitud incorrecta, si se trata de un discurso pronunciado durante un entierro: una actitud inapropiada en ese contexto. En mi opinión, ejemplos como éstos ponen en evidencia, antes que nada, el carácter eminentemente contextual de la noción goodmaniana de corrección pragmática. Se trata siempre de que una emisión (una palabra, una imagen, un gesto, etc.) sea relevante, más aún, que calce en una determinada situación, y de que conduzca a ciertos efectos, que a su vez sólo importan en vista de intereses y necesidades que precisamente distinguen una situación de otra. Este énfasis en lo contextual se halla presente también en el esbozo general que Goodman y Elgin, a falta de una definición rigurosa, ofrecen del concepto en cuestión: "[l]a corrección pragmática (rightness) es una cuestión de calzar (fitting) y de funcionar (working)", ${ }^{22}$ esto es, de ajustarse a un cierto contexto o discurso, y de ser funcional a determinados propósitos. Es imposible pasar por alto

22 Goodman/Elgin, op. cit., p. 158. Dejo sin considerar la tesis de que la corrección pragmática es además "multidimensional", i.e., aplicable no sólo con relación a lo que se dice, sino también a otros modos de funcionamiento simbólico, como la ejemplificación, la expresión o la alusión. 
la generalidad y hasta la vaguedad de esta caracterización, pero no me parece que esto sea culpa de Goodman o Elgin. La imposibilidad tanto de una definición general como de criterios exactos, refleja precisamente el hecho de que se esté proponiendo una categoría contextual. Afirmar que la corrección pragmática de un símbolo (en el sentido amplio en que Goodman habla de "símbolos") es siempre relativa o sensible a un contexto, equivale a negar que existan criterios fijos para dar con ella. De ahí que la caracterización algo imprecisa de rightness no nos deba preocupar más que la imprecisión en que necesariamente "caemos" al tratar de explicar qué es un contexto. Determinar que algo es correcto o adecuado no es ni más fácil ni más difícil que aprehender un contexto o ubicarse en una situación. Se trata en ambos casos de una capacidad práctica, cuya adquisición y funcionamiento no se rige por reglas precisas.

Esta presentación del concepto de rightness apunta al primer motivo por el cual lo considero un concepto relevante para el asunto que nos ocupa. El punto es que la metáfora es un fenómeno lingüístico que lleva también la marca de lo contextual y en que lo contextual tiene como contraparte la imposibilidad de una reglamentación. Si una oración es dicha metafóricamente o no, es algo que depende de una situación comunicativa, es decir, de aquel que habla o escribe, de su público, de los temas de interés, de las informaciones compartidas, etc. Cuando alguien dice, por ejemplo, que Juan es un niño, puede querer decirlo en un sentido literal, en el caso de que Juan tenga seis años, o en un sentido metafórico, si se refiere a un Juan de treinta. Y cuando alguien pregunta, si las flores se van a dormir todas las noches, no necesariamente se trata de una metáfora: quien pregunta podría ser un niño que aún no domina plenamente el uso del verbo "dormir". Lo que vale para la identificación de un enunciado en cuanto metafórico, vale por cierto aún más para su interpretación. 
Sólo podrán interpretar propiamente una metáfora, sólo se interesarán incluso por hacerlo, quienes dispongan de informaciones que el autor está presuponiendo, quienes conozcan el trasfondo necesario para que una metáfora tenga gracia. ${ }^{23}$ Nótese que esta dependencia contextual vale también para metáforas muy generales, como las dos metáforas filosóficas sobre el lenguaje que cité al comienzo. En casos como éstos, el contexto en el que la metáfora ha de calzar es un contexto de preguntas, problemas, discusiones, etc. Quien no esté mínimamente al tanto de maneras tradicionales de concebir filosóficamente el tema del significado lingüístico, no reparará en el tremendo potencial crítico que implica ver las palabras como herramientas. Ahora bien, a toda esta dependencia contextual le corresponde, como el reverso de una misma medalla, la inexistencia de reglas. No es casual que no existan diccionarios de significados metafóricos, es conceptualmente necesario. Pocos querrán negar que sería absurdo pretender formular reglas fijas y necesarias para la producción de metáforas; pero esto vale también para su identificación e interpretación por parte del oyente o el lector. Pues bien, la idea goodmaniana de corrección pragmática nos permite ver que el carácter necesariamente contextual y, por ello, no reglamentado del fenómeno metafórico no excluye la posibilidad de una evaluación normativa. Una metáfora puede ser evaluada, primero, en el sentido de si es apta o apropiada en un determinado contexto lingüístico o extralingüístico $\mathrm{y}$, segundo, si consigue realmente los efectos que son de relevancia e interés en tal contexto.

Es cierto que lo primero - el engarce con un discurso o contexto - no representa un parámetro de acuerdo con

23 Cohen explicita, a partir de esta observación, una muy interesante función social del discurso metafórico: la de crear intimidad. Cfr. Ted Cohen, "Metaphor and the Cultivation of Intimacy", en S. Sacks (ed.), On Metaphor, Chicago, 1979, pp. 1-10. 
el cual midamos exclusivamente enunciados metafóricos. En particular, ser relevante y calzar en una situación dada es una exigencia a la que también se halla sometido el discurso literal (a éste le exigimos normalmente ambas cosas: verdad literal y adecuación pragmática). Pero el ajuste contextual posee para el enunciado metafórico, a diferencia del literal, una importancia de vida o muerte. Como puede observarse sobre todo en metáforas osadas o inusitadas, es precisamente tal ajuste el que nos permite decidir si lo escuchado o leído es siquiera una metáfora o si no es, en realidad, un simple abuso del lenguaje. Cuando la vida humana es llamada una comedia, un libro, un viaje, un baile de máscaras, etc., no resulta difícil constatar un empleo metafórico del lenguaje. Pero, ¿qué diríamos si alguien afirma sin más que la vida es una zanahoria, una piscina o un clavo? Por cierto, es posible construir o imaginarse un contexto lingüístico o extralingüístico en que semejantes afirmaciones adquieran un sentido metafórico (en un artículo sobre metáfora leí que existe efectivamente un poema basado en la idea de que la vida es una zanahoria). Pero si no disponemos de tal contexto, tenderemos a ver en casos como éstos enunciados sin sentido alguno, puro nonsense. Para la metáfora, sobre todo en el caso paradigmático de metáforas que sorprenden y refrescan, el ajuste contextual es entonces cuestión de vida o muerte, pues a falta de tal ajuste lo dicho tiende a degenerar en mero sinsentido.

Dicho sea de paso, este ajuste a una situación apunta a otro elemento característico del discurso metafórico y del discurso figurado en general. No por nada hablamos a menudo de la metáfora "precisa". Estoy pensando en el tono. Buenas metáforas adecuan su tono, o bien solemne y elevado, o bien común y corriente, según lo que esté en juego. Si se trata de proponer una profunda visión sobre un tema crucial de la vida, se evitará un tono ligero. Pero 
si el contexto es cotidiano y lo que se busca es conseguir un efecto directo y sencillo, por ejemplo mediante una imagen plástica, el tono no puede ser sublime. Se me objetará que cuando hablamos literalmente también importa el tono. Y responderé que es cierto, pero que la preocupación por la palabra justa, el matiz preciso o el tono adecuado no es tan característica del discurso literal. Existen, sin duda, descripciones completamente literales que evidencian un enorme cuidado por el tono, los matices, etc. - baste pensar en la prosa de un escritor que no ocupa metáforas. Y también hay situaciones cotidianas en que es decisivo no sólo qué se diga, sino cómo se diga... literalmente. Pero hay también muchas otras en que no lo es, situaciones en que no mostramos tal cuidado, pues nuestro interés se limita al traspaso de una simple información que puede ser expresada de una forma u otra. Lo que aquí quiero decir es que en el discurso metafórico esto no ocurre nunca. Con relación a todo este asunto existe, es cierto, una diferencia más bien gradual entre lo literal y lo metafórico; pero la diferencia existe.

Un segundo aspecto iluminador de la noción goodmaniana es el siguiente: no porque entre los encantos de la metáfora se cuenten sus efectos no proposicionales, no porque enfaticemos su capacidad de inspirar imágenes o escenarios, actitudes o sentimientos, no por ello tenemos que guardar silencio - como sugiere Davidson - respecto de si un enunciado metafórico es en sí mismo correcto o no. Me limitaré a reseñar este punto mediante un ejemplo. Un hombre y una mujer que han vivido juntos toda una vida, se enfrentan con el hecho de que su amor ha ido desapareciendo con el tiempo, de que su relación carece ya de sentido. Una noche, tras una larga y difícil conversación en la que vuelven a constatar la ausencia de sentimientos mutuos, los invade a ambos una profunda tristeza. Uno de ellos dice entonces en voz baja: "Está anocheciendo...". 
Si bien es verdad que afuera anochece, esto es demasiado verdadero y, por lo demás, irrelevante. Se trata de una metáfora; una metáfora quizá no muy original, pero correcta en el sentido goodmaniano. Por un lado, el verbo "anochecer" y sus connotaciones —un cierto silencio, una cierta melancolía - calzan, es decir, son oportunos en ese momento de gran desconsuelo. Y por otro lado, la palabra dicha consigue el efecto metafórico apropiado. Naturalmente no se trata en este caso de un efecto cognoscitivo - la otra persona también sabe que ya todo ha terminado. El hablante ha querido más bien poner énfasis en la tristeza que siente y sabe compartida; de alguna manera ha querido incluso suscitar aquel sentimiento de tristeza que considera el único indicado, conveniente a la situación. Acaso haya querido evocar a la vez un cierto recogimiento y - junto con éste - una cierta tranquilidad, que son parte de lo que solemos asociar con anocheceres y que perfectamente pueden ir de la mano con la tristeza. Como se aprecia, incluso en casos tan sencillos como éste, la metáfora puede traer consigo una compleja gama de sentimientos apropiados y ha de ser considerada en tal medida una metáfora adecuada, correcta. Pero esto significa que sí es pertinente - a diferencia de lo que sugiere Davidson - evaluar una métafora en términos normativos, pese a que haya aspectos no proposicionales en juego. Sólo es necesario tener en cuenta que ciertos sentimientos son en ciertas ocasiones los apropiados.

Pero volvamos a la función cognoscitiva del discurso metafórico, que, sin negar otras funciones que indudablemente tiene, es la que me interesa aquí centralmente. El concepto de corrección pragmática - y éste es el tercer aspecto que quisiera destacar al proponerlo como un concepto clave para nuestro tema - nos da una primera idea del modo en que una metáfora puede cumplir un papel cognoscitivo. Recordemos la lista de Goodman y Elgin: entre 
sus ítems, es decir, entre las cosas de las que diríamos que pueden ser correctas pragmáticamente figuraban dibujos, fotografías, mapas geográficos y diagramas. Pues bien, lo común a estos casos es que en cada uno de ellos alguien se sirve de un medio determinado para mostrar y no para decir "cómo son las cosas" en un ámbito determinado. ¿No es posible afirmar algo semejante del modo en que una metáfora puede ser relevante cognoscitivamente? ¿Y no tendrá que ver la resistencia de Davidson a buscar un concepto de verdad metafórica con su no consideración de dibujos, fotografías, mapas y otros "símbolos" en cuanto medios de conocimiento? Ciertamente todos ellos son medios genuinamente cognoscitivos, procedimientos de los que nos valemos para saber "cómo son las cosas" en un ámbito determinado. $\mathrm{Y}$ en el hecho de que lo sean no parece haber tampoco nada misterioso, otro de los motivos - lo misterioso - que seguramente tornan sospechosa la noción de verdad metafórica a los ojos de Davidson. Lo dicho sobre dibujos, fotografías, etc., vale también para el lenguaje gestual: un gesto es considerado correcto (right), si quien lo ejecuta logra mostrarnos "cómo son las cosas", tanto en los casos más sencillos — como cuando con un movimiento de la mano indicamos que queremos la cuentacomo en casos más complejos. El famoso gesto napolitano con que Piero Sraffa le hiciera ver a Wittgenstein las limitaciones de su posición semántica en el Tractatus fue, en el sentido más goodmaniano, el gesto apropiado. ${ }^{24} \mathrm{La}$ categoría de rightness nos permite apreciar entonces que al hablar metafóricamente más que decir algo, lo que pretendemos es mostrar algo. La metáfora de las palabras como

24 Un buen análisis de este gesto y del lenguaje corporal en general con relación a consideraciones estéticas de Wittgenstein, se encuentra en Karl Heinz Lüdeking, "Bild und Gebärde. Ludwig Wittgensteins Philosophie des Ausdrucks", Neue Rundschau, 99, 1988, pp. 115135 .

92 
herramientas nos hace ver el significado y el lenguaje de otro modo, sin que diga o exprese algo adicional a lo que en realidad dice: una obvia falsedad. Un enunciado metafórico muestra algo interesante, diciendo algo absurdo o trivial, y en tal sentido no es tanto un enunciado, como más bien un gesto (esto podría considerarse una observación gramatical al concepto de metáfora). Y, por supuesto, podemos tener éxito pero también fracasar en el intento de mostrar algo: las metáforas pueden ser correctas o incorrectas. ${ }^{25}$

El concepto goodmaniano de corrección pragmática, aplicado a la metáfora, revela una gramática distinta de la del concepto de verdad literal. Es una especie de error categorial pensar que una metáfora diga algo correcto, al modo de un enunciado literal: el decir no es su negocio. Si se quiere, un enunciado metafórico no es un vehículo de conocimiento, sino una ventana al conocimiento. Relacionado con todo esto hay otro aspecto gramatical que subrayar: es propio del mostrar, más que del decir, el carácter abierto o indeterminado que, como vimos en la primera parte, caracteriza al enunciado metafórico. No es claro cuánto sea capaz de mostrarnos una fotografía, pero sobre todo no es claro que quepa preguntárnoslo. Y lo mismo ocurre también, como ya vimos, con la metáfora.

A modo de resumen: la hipótesis con que hemos trabajado en este apartado, la hipótesis de que la verdad de una metáfora consista en ser correcta, en el sentido goodmaniano de corrección pragmática, tiene la triple ventaja de: a) subrayar el carácter contextual del fenómeno metafórico, b) hacer justicia a los momentos no proposicionales - pero no por ello arbitrarios - de una metáfora y c) hacernos tomar conciencia de que el modus operandi de la metáfora no es, en primer lugar, un decir, sino un mostrar, lo que pone

25 La analogía entre metáforas y mapas, gráficos, fotografías, etc., es apuntada también por Black. Cfr. Max Black, op. cit., p. 456. 
ya de manifiesto diferencias gramaticales entre la verdad metafórica y la verdad literal.

\section{Crear un contexto adecuado}

Por dos motivos — que creo relacionados - lo alcanzado hasta ahora es aún insuficiente. En primer lugar, cuando preguntamos en qué sentido es verdadera una metáfora, lo que nos interesa es averiguar en qué sentido lo es de su objeto, es decir, del objeto o tema sobre el cual versa. Lo que he planteado hasta ahora, valiéndome de la rightness goodmaniana, es que la metáfora debe ser apta con relación a un contexto; aunque esto sea parte importante de la historia, como creo que lo es, no puede ser la historia completa. Y en segundo lugar, la tesis de que nuestra actitud e intención al hablar mediante metáforas corresponden a un mostrar y no a un decir, si bien ayuda a entender por qué razones "gramaticales" no procede analizar la verdad metafórica en términos de verdades literales, i.e., verdades "dichas", como tesis positiva resulta ser terriblemente vaga. Peor aún, mapas y gestos son capaces de mostrarnos cómo son las cosas, con base en sendos sistemas convencionales de representación (aunque esto no vale para el uso no convencional que Sraffa hace del gesto napolitano). Sin embargo, en el caso de la metáfora - $\mathrm{y}$ he hecho precisamente mucho hincapié en esto- no existen convenciones o reglas en la base de su funcionamiento. Resumiendo, la tesis de que una metáfora muestra algo, en vez de decirlo, no es más que el anuncio de una explicación.

Empezaré por este segundo punto, la distinción entre decir y mostrar, para luego conectar con el primero, la verdad de una metáfora con relación a su objeto. Observaba hace un momento que la metáfora muestra algo interesante diciendo algo absurdo o trivial. La observación no era, nótese bien, que la metáfora muestre algo sin decir na- 
da, ni que lo dicho dé lo mismo. He ahí la razón de por qué la comparación metafórica entre gestos y metáforas sea tan insuficiente y de por qué esto valga incluso para el caso de Sraffa. Sraffa usó no convencionalmente un gesto convencional; tal original uso calzó en una situación, logró un efecto cognoscitivo relevante (le mostró a Wittgenstein "cómo son las cosas") y puede ser considerado por ello correcto, adecuado. Todo esto puede decirse también de un enunciado metafórico. Pero hay una diferencia que salta a la vista: el enunciado metafórico posee, esto es un hecho, un contenido proposicional. La función cognoscitiva de una metafóra no puede consistir en algo que nos dice. Pero la metáfora nos muestra lo que nos muestra diciéndonos algo, i.e., valiéndose del contenido que expresa. Por lo mismo, ese contenido, aunque falso u obviamente verdadero, no puede ser irrelevante. En él radica más bien la forma específica - la que ahora debiéramos describir - en la que los enunciados metafóricos, a diferencia de "símbolos" como gestos, mapas o fotografías, pueden mostrarnos algo. ¿Qué función desempeña dicho contenido?

En mi opinión, la mejor manera de describir la función del contenido falso u obviamente verdadero de una metáfora es diciendo que, a través de él, quien habla o escribe metafóricamente crea un nuevo contexto y lo propone como adecuado para hablar (y no sólo hablar) de un cierto objeto o tema. Quien afirmó por primera vez que la pobreza es un delito, creó un nuevo contexto en el cual situar el tema de la pobreza y afirmó que se trataba de un contexto adecuado con relación a ese tema. Ese contexto es el que forman no sólo todas las informaciones, sino también todas las imágenes, estados de ánimo, formas de reaccionar, etc., relacionados con el fenómeno del delito. Como es obvio, no cualquier falsedad da lugar a una buena metáfora. Lo que torna a algunas de ellas interesantes - a diferencia de, por ejemplo, "Una silla es un silogismo"- 
es su capacidad de indicar un contexto adecuado para la tematización de un asunto. Vemos ahora que una metáfora opera cognoscitivamente de un modo más complejo que el gesto de Sraffa y mucho más complejo que un gesto o un mapa convencional: una metáfora crea — y ahí radica la función de su contenido proposicional - un nuevo contexto para hablar del tema en cuestión y relacionarse con él. Es por eso que la metáfora muestra, si se quiere, mucho más que un gesto o un mapa, o muestra "cómo son las cosas" en un sentido a la vez más profundo.

Para dar más forma a la idea que estoy proponiendo - la idea de que mediante una metáfora se crea un contexto, del cual se afirma a la vez que es correcto o adecuado- examinemos brevemente los dos conceptos en juego: contexto y contexto adecuado. Al hablar de "contexto" quiero llamar la atención sobre algo que puede ser igualmente descrito mediante otras nociones. Podemos decir, por ejemplo, que la falsedad de la oración "Las palabras son las flores de la boca" sirve para crear y proponer un nuevo modo de ver el tema del lenguaje. $\mathrm{O}$ podemos decir que el error categorial contenido en la oración "La arquitectura es música petrificada" brinda un nuevo acceso al tema de la arquitectura, una nueva perspectiva sobre la arquitectura. Reuniendo estos conceptos — "contexto", "modo de ver", "acceso", "perspectiva" - quiero recalcar lo que cada uno de ellos sugiere: a saber, el hecho de que un contexto -o un modo de ver, una perspectiva, etc.,- no se agota en un conjunto de enunciados o pensamientos, i.e., de estructuras proposicionales, sino que abarca también - como apunté ya en el ejemplo del delito - formas de actuar y reaccionar, actitudes, imágenes, sentimientos, etc. Un modo de ver algo no es simplemente un conjunto de opiniones más o menos bien conectadas lógica y temáticamente. Un modo de ver algo - simplemente por tratarse de un modo - no se puede decir; si bien incluye enunciados particulares, no se agota 
en ninguno de ellos, escapando siempre a su reproducción en un listado de verdades. Como bien señala por ahí Dummett con relación a lo que Wittgenstein buscaba con su filosofía y que éste mismo caracterizara precisamente como una Anschauungsweise, un nuevo modo de ver el lenguaje: "Una mirada límpida no es a su vez un objeto visible." 26

Ahora bien, ¿qué significa hablar de un contexto adecuado o un modo de ver correcto? Si bien se trata de las mismas palabras usadas por Goodman y Elgin, su uso ya no es el mismo; se trata ahora de un concepto diferente. Ya no estamos hablando de un enunciado (literal o metafórico), una palabra, un estado de ánimo, etc., que es correcto o adecuado con relación a un contexto; hablamos ahora de un contexto que puede ser correcto o adecuado con relación a un tema. Pues bien, la fundamental diferencia estriba en que es imposible hablar de un contexto correcto o adecuado prescindiendo de la noción habitual de verdad, i.e., de verdad proposicional. Veíamos en Goodman que, dado un cierto contexto, un mismo enunciado puede ser falso y no obstante correcto, como en el caso del médico y el paciente desalentado, o puede ser verdadero pero incorrecto, como en el caso de "La nieve es blanca" en medio de una discusión sobre el granito. Pero la posibilidad de que la corrección pragmática siga un camino distinto del de la verdad, no existe cuando de lo que se trata es de saber si un contexto es el correcto, el adecuado, o no. Un contexto, un modo de ver o un acceso no pueden ser considerados correctos si los enunciados a los que dan lugar no son verdaderos. Que un contexto sea el adecuado para situar un tema, para hablar de él y relacionarse con él, significa, entre otras cosas, que da pie a la elaboración y

26 Dummett, Michael: "Can Analytical Philosophy be Systematic, and Ought it to Be?", recopilado en su Truth ond other Enigmas, Cambridge, Mass., 1978, p. 439. 
reconocimiento de verdades literales. Ahora resulta posible explicar la intuitiva plausibilidad que posee el modelo de la verdad indirecta, con su énfasis en las verdades literales a las que una metáfora es capaz de conducirnos. Una condición necesaria para que una metáfora sea considerada correcta con relación a su objeto es que nos conduzca a verdades literales sobre el mismo -ésta es la intuición correcta que subyace en el modelo de la verdad indirecta. Sin embargo, dicho modelo distorsiona otros dos aspectos igualmente centrales: primero, que la función del habla metafórica no es la de expresar un mensaje cifrado, sino la de crear y proponer un contexto o modo de ver; y, segundo, que por el carácter propio de nociones como "contexto" o "modo de ver", la verdad de una metáfora no se agota en conducirnos a verdades literales. Un contexto adecuado a un tema o un modo de verlo correctamente constituye un complejo entretejido formado por creencias verdaderas $y$ actitudes, prácticas, emociones, etc., correctas (también, ahora sí, en un sentido de validez normativa y moral) respecto de un tema.

Este enfoque hace justicia a aquellos aspectos característicos de lo metáforico con los que el modelo de la verdad indirecta entra en conflicto. Primero, el carácter abierto de la metáfora, el repetido "etcétera" en que acaba su interpretación o comentario, queda directamente reflejado en el carácter indeterminado de la noción de contexto. El contexto creado por una metáfora permite una cantidad de enunciados literalmente verdaderos sin un límite claro. Segundo, no existe razón alguna para negar que un modo correcto de ver un tema puede incluir perfectamente modos metafóricos de hablar sobre el mismo. Tercero, y como he venido enfatizando ahora, un modo de ver un tema no sólo nos permite decir literal y metafóricamente muchas cosas, sino también relacionarnos de otra manera con él (pensemos en el caso de la pobreza como delito), lo que 
muestra la relevancia de los aspectos no proposicionales del discurso metafórico. Y, cuarto, el enfoque da cuenta también del papel activo del intérprete: el hablante propone un contexto (lo que, obviamente, no es poco), pero es el intérprete quien opera dentro de él, quien averigua sus posibilidades, quien termina sacándole partido o no.

A la luz de lo dicho podría presentarse el siguiente reparo: ¿es lo que estoy proponiendo como función cognoscitiva de una metáfora - la articulación de un modo acertado de ver las cosas - realmente una función específica del discurso metafórico? ¿No se trata acaso de una función que puede ser cumplida igualmente por el discurso literal? Si alguien dice la oración: "Somos los habitantes de un pequeño planeta en medio del universo infinito", ¿no está acaso articulando también un complejo modo de ver la vida humana, incluidos sentimientos, actitudes, formas de actuar, etc.? Para responder a esta objeción es necesario preguntar por la situación en que la oración es proferida y puede cumplir la función descrita. Se trata con toda seguridad de una situación en que el contenido literal de lo dicho no cuenta como especialmente informativo, por ejemplo, durante una conversación entre un grupo de adultos relativamente bien informados al comenzar el siglo XXI. En ese contexto, el hecho de que somos habitantes de un pequeño planeta en medio del universo infinito es cuestión bien conocida, prácticamente obvia. Ahora bien, sólo habiendo supuesto un contexto como éste, se ha podido describir la función de lo dicho como se acaba de describir. En otras palabras, se la ha podido describir así, porque en ese contexto no explicitado estamos en realidad frente a un uso metafórico de la oración. Sería distinto si se tratara de un grupo de niños a los que un profesor explica por primera vez el tamaño de nuestro planeta, o de un extraterrestre extraviado que nos pide información sobre el mismo. Lo que se olvida, al presentar este supuesto contraejemplo, es que lo metáforico 
no es una propiedad de determinadas oraciones, sino más bien una manera de usarlas por parte de un hablante y de interpretarlas por parte de una audiencia.

Termino con una observación crítica sobre aquella filosofía en la que de alguna manera me he formado: la así llamada filosofía analítica. De lo que he planteado aquí se sigue, me parece, la necesidad de corregir una imagen torcida con relación al tema de la verdad, a saber, la imagen que nos dejan los filósofos analíticos con su casi obsesión por el tema de la verdad proposicional, i.e., por el predicado "verdadero" cuando se dice de oraciones o creencias. Hablo de una imagen "torcida", en vez de "falsa", pues no se trata ni de un error, ni de una suma de errores, que alguna de las "teorías de la verdad" en circulación pueda corregir redistribuyendo los valores de verdad asignados a sus proposiciones. Se trata más bien de una fijación, de una imagen que mantiene cautivo, de unas gafas a través de las cuales se mira todo, en suma, de un determinado modo de ver la temática de la verdad. ${ }^{27}$ Acaso quepa especular que la conformación de una imagen distinta de la verdad requerirá necesariamente, además de buenos argumentos, de nuevas y sugerentes metáforas. Pero en cualquier caso, mientras no se nos ocurra quitarnos las gafas, no seremos capaces de ver que tanto en nuestra vida cotidiana, como en nuestras ocupaciones intelectuales, políticas y artísticas, existen formas de verdad, o si se quiere, de lo correcto o apropiado, no susceptibles de ser identificadas con, ni reducidas a, la verdad proposicional. La "filosofía analítica" — si es que este rótulo designa hoy en día algo más que entidades geográficas e institucionales (países, facultades o revistas, a diferencia de contenidos, métodos o estilos) -

27 Estas expresiones son obviamente prestadas. Cfr. Ludwig Wittgenstein, Investigaciones filosóficas, Barcelona, 1988, §§115, 103 y 144 . 
no pareciera tener cabida para formas no proposicionales de verdad. Davidson tiene toda la razón en negarle a la metáfora verdad proposicional. La cuestión es si no hay otros tipos de verdad.

Recibido: 7 de junio de 2000 


\section{SUMMARY}

What does the (possible) truth of a metaphor consist in? The first part of this paper is a critical analysis of the following model: A metaphorical statement is true if and only if it somehow leads to the recognition of literal truths. This model of metaphorical truth as indirect literal truth is not utterly inadequate, but it fails to account for certain central features of the metaphorical: the openness of the interpretation of living metaphors, the phenomenon of the so called metaphorical chains (or nets), the non-propositional aspects of many metaphors, and the active, creative role of the interpreter.

In the second part I develop an alternative model, based on: a) a pragmatist methodology with respect to the truth-issue in general (truth without representation), b) Goodman's concept of rightness, c) the difference between saying and showing, and d) the idea, that a good metaphor creates a new context which not only allows us to say something new concerning the topic in question, but which allows us to treat the topic in a new manner. 